of Agriculture has made a grant of $3100 l$. out of the Development Fund, and has also promised an annual maintenance grant of $2500 l$. from the same source. These grants are made on the "pound for pound" principle, i.e. they are given subject to an equal amount being raised from other sources. The Society for the Extension of the Rothamsted Experiments was founded for the purpose of collecting subscriptions, and is now making a further appeal. Subscriptions and donations should be sent to the secretary, the Rothamsted Experiment Station, Harpenden.

It is hoped to raise 6oool. as the centenary .fund, and thus to qualify for a further grant of $6000 l$, making a total of $\mathrm{r} 2,000 l$, a sum which it is estimated will give buildings and appliances adequate for some years to come.

\section{THE GLASGOW MEETING OF THE}

\section{INSTITUTION OF NAVAL ARCHITECTS.}

THE Institution of Naval Architects held a successful and largely attended summer meeting in Glasgow on June $23^{-27}$. An interesting series of visits to works and excursions had been arranged, that to Messrs. Beardmore's shipyard, and the excursion to Arran with which it was combined, proving particularly enjoyable. While most of the papers dealt with purely technical matters, one or two were of more general interest.

In a paper on safety of life at sea, Mr. Hillhouse summed up the present state of affairs from the point of view of the naval architect. Apart from careful navigation the three factors on which we have to rely are wireless telegraphy, subdivision of hulls, and a sufficiency of boats. Of these, the adequate subdivision of hulls presents very serious constructional difficulties, and offers few advantages in the case of fire, while it is almost impossible to provide sufficient small boats and to guarantee that they shall all be usable in the moment of emergency. The one thing on which we can insist is careful navigation, although this may involve some reduction in speed.

Dr. S. J. P. Thearle directed attention to a number of cases in which cracks have developed in the sheil plating of a steel vessel at points removed from rivetholes and from the edges of the plate. These have been found to occur only in the vicinity of a frame unsupported by any beam, and are evidently due to "fatigue" following alternate stressing of the plate by "panting."

In a paper on the effect of form and size on the resistance of ships, Mr. J. S. Baker dealt with the effect of an increase in the length of the parallel portion of a vessel and of fullness of form. The problem was first attacked from a theoretical point of view on the assumption of stream-line flow; the distribution of pressure around the hull was computed; and a law deduced for the speed at which transverse wavemaking occurs. These results were compared with those obtained from model experiments, and from these the author deduces an expression for the most economic length of parallel body to be associated with a given entrance and run.

Prof. A. H. Gibson and Mr. Hannay Thompson read a paper dealing with the theory of "suction," or interaction between passing vessels, and with an extensive series of experiments carried out to investigate this important question. The vessels used were respectively $90 \mathrm{ft}$. and $30 \mathrm{ft}$. in length, displacing respectively 96 and $2 \cdot 6$ tons. The experiments were divided into two sets, one dealing. with the behaviour of the vessels when moving at different distances apart and at different speeds with helms lashed amidships, and the other dealing with the helm angles necessary to maintain a straight course and with the forces and moments operative to produce deflection of the course under similar conditions. The experiments were carried out in deep and open water, and the authors conclude that even in these circumstances interaction is a very real danger to navigation under certain conditions. The danger would appear to be greatest when the larger vessel is passing the smaller in fairly close proximity at a speed not greatly in excess of that of the smaller. In such circumstances, particularly if the larger be at the time accelerating with a view of drawing out of range of the smaller, the latter may be drawn into collision, except in so far as prevented by the helm, from distances as great as three or four lengths of this vessel. With the vessels within one length of each other the helm required to keep the smaller on its original course varied with its longitudinal position relative to the larger, and with their relative speeds. When all circumstances favoured interaction a helm angle of as much as $20^{\circ}$ was necessary to prevent collision. Generally speaking, since the helm effect increases somewhat more rapidly than that of suction, a vessel is more easily controlled against these forces at high than at low speeds.

An interesting paper by $\mathrm{Mr}$. A. Cannon records the results of experiments with an apparatus designed by Sir H. Biles on principles laid down by Colonel Russo, R.I.N., to investigate the effect of internal loose water upon the rolling of a ship amongst a regular series of waves, while a paper by Mr. Lloyd Woodward, dealing with the theory of the same subject, forms a useful supplement to this. The experiments point to the conclusion that, generally speaking, the addition of free water decreases the angle of roll, and always does so if its quantity is limited. If, however, the quantity is fairly large, and particularly in short and high waves, the effect is to increase the angle, and under a certain combination of wavelengths and height the angle may become dangerous. Further, these large angles are attained in a very few rolls, and it is quite possible for them to be attained in an actual ship, although the resistance to roll may be very great.

In a paper which was taken as read, Prof. L. Gümbel dealt with the cavitation of screw propellers, concluding that the tendency to cavitation not only increases with a diminution in the depth of immersion and with the amount of dissolved air in the water, but also depends very largely on the pitch of the propeller, on the angle formed by the feather edge in the cross section of the blade, and on the amount of slip. As regards the latter point, the limit of slip which may take place without cavitation is reduced as the speed of the vessel increases. On the other hand, the occurrence of cavitation is not dependent on the surface pressure over the blade area. A small angle at the emersion edge is more easily obtained with a broad-bladed propeller than in one with narrower blades. In this fact lay, in the author's opinion, the secret of the success that had been obtained with turbine screws with broad blades. Since, however, broad blades involve increased friction, an attempt should be made to so form the cross section as to get a narrow blade with the minimum possible angle of emersion.

Other papers descriptive of the results of trials on modern vessels propelled respectively by geared turbines and by Diesel engines enable an interesting comparison to be gained between the performance of these types of motor. In the turbine installation of 2400 b.h.p. the steam consumption was only $12.551 \mathrm{~b}$. per shaft h.p., the ratio of effective h.p. to shaft h.p. attaining a maximum value of about $5^{8}$ per cent. at No. 2279 , VOL. 9I] 
about 480 revolutions per minute. With the Diesel engines, of 1000 h.p., the remarkably low consumption of $0.37 \mathrm{lb}$. of oil per shaft h.p. was obtained.

In the concluding paper of the meeting Messrs. Reid and Mavor made out an excellent case for electrical propulsion in conjunction with Diesel engines in the type of large canal barge or freighter used to such an extent on the great inland waterways of North America. The efficiency of such a vessel depends very largely on the ease and rapidity with which it can be manœuvred, reversed, accelerated, and backed, during its frequent passages through the locks on these waterways, and this puts the directcoupled Diesel engine, under present conditions, out of court.

\section{THE NATIONAL PHYSICAL LABORATORY}

\section{Opening of New Building.}

THE new building at the National Physical Laboratory, Teddington, was opened by the Right Hon. A. J. Balfour on the day of the annual visitation, Thursday, June 26 . The opening ceremony was held in the structure designed for the new wind-channel for aëronautical work. A large and distinguished company foregathered, including Sir Archibald Geikie, who presided, Colonel Seely (Secretary of State for War), Lord Rayleigh, Lord Allerton, Lord Welby, Viscount Esher, Lord Montagu of Beaulieu, Sir Oliver Lodge, Sir Wm. Crookes, Sir Wm. Ramsay, Sir John Brunner, Sir Albert Spicer, and Dr. R. T. Glazebrook (director of the laboratory).

The chairman, in his opening remarks, referred to the amazing growth of the laboratory and the place it had taken as one of the most important national institutions in this country.

Dr. Glazebrook dwelt on the noble liberality of the friends who had so splendidly supported the laboratory in the past, and Lord Rayleigh emphasised the fact that funds were still needed for equipment purposes. Lord Rayleigh went on to express the hope that in the future larger funds would be available to enable greater attention to be paid to research in pure science, as well as to work calculated to further the immediate ends of industry.

Mr. Balfour gave an interesting and thoughtful address dealing largely with the national advantages of the study of pure science. In the course of his address he remarked:-

Measuring is the very life-blood of physical science. It lies at the root of almost all great discoveries and their application to practice. It is impossible not to acknowledge the benefit which mankind has received by the command which science has given us; and measurements and testing are absolutely essential to science. The great features of a national laboratory are its impartiality, its ability to bring an adequate staff and adequate machinery to bear on problems, and the standard of perfection which it sets for instruments and which serves as an ideal for manufacturers to work to. The advantages to industry are beyond all doubt and beyond all question.

But the successes of the future of industry depend on the abstract of purely scientific investigations of the present, and it is to the labours of the man of science worling for purely scientific ends, and without any thought of the application of his doctrines to the practical needs of mankind, that mankind will be most indebted as time goes on. The general public does not realise that it is to the results of pure science that we have owed in the past, and shall owe more and more in the future, all oreat advances in indus- trial knowledge and practice. Still less does it realise that the man of science who is working continuously towards that end is only. half a man of science, and is not likely to do his scientific work nearly so well as if he were simply and solely occupied in advancing that branch of knowledge with which he is connected.

When these important truths have sunk into the public mind, we may see, as a reflection of that new conviction, a different attitude adopted by those who have to settle what expenditure should be presented to Parliament for its sanction, and the attitude which Parliament itself may take in the face of such suggestions. The growth of this great institution during its very few years' existence justifies us in looking forward to a great and glorious future for it. The thanks of the public are due to the brilliant and hardworking staff of the laboratory who, under no small difficulties, are the real authors of the triumph which we are met to celebrate.

After the opening ceremony, an inspection was made of the new building, and visitors wandered at will through the various departments of the laboratory, in which a series of interesting demonstrations had been arranged.

The new building marlzs the completion of a scheme for the erection of laboratories for metallurgy and optics, and of a building for administration purposes. The late Sir Julius Wernher made himself responsible for the funds for the metallurgical laboratories, and for the rest, the Treasury, the $185^{\prime}$ Commissioners, and some of the City Companies have made generous contributions.

One of the main objects for which the new laboratories have been erected was to enable the testing work, until recently carried out at Kew Observatory, to be transferred to Teddington. Kew Observatory is in future to devote itself purely to meteorological objects-it is now, in fact, the central observatory of the Meteorological Office--while the testing of instruments of all kinds will be undertaken exclusively at Teddington.

The new building provides accommodation for the administration and optics departments, together with workshop and packing rooms. The optics wing is designed to accommodate the optical testing work hitherto carried out at Kew and in a suite of rooms at Bushy House. The latter rooms are now occupied by the thermometer-testing observers from Kew, while the remainder of the Kew test-work has been housed in the metrology department.

The new building, of which we show an illustration is a three-storey structure built of purple Surrey bricks with red brick facings. The architecture is of the Queen Anne period, and the structure bears a general resemblance in style to Bushy House, alongside which it stands, and which, it will be recalled, formerly housed the whole of the work of the laboratory. The new building impresses one as being generously lighted and very substantially built, and reflects great credit on the architect, Mr. W. D. Caröe, and on the clerk of the works, Mr. R. Allen Jane.

Great care has been bestowed on the fireproof qualities of the building; the floors and stairs are of ferroconcrete throughout, and generous provision has been made for fire hydrants. This feature is, of course, doubly important in a building one of the functions of which is to house important records.

The ventilation is controlled by a large fan on the roof, communicating by ducts to extractors in the ceilings of the different rooms. Fresh air is admitted through louvres behind steam-heated radiators provided with suitable baffle plates.

The corridors throughout are covered with Dolo-

NO. 2279, VOL. 9I] 